\title{
Classic glucose transporter type 1 deficiency syndrome
}

INSERM

\section{Source}

INSERM. (1999). Orphanet: an online rare disease and orphan drug data base. Classic glucose transporter type 1 deficiency syndrome. ORPHA:71277

Glucose transporter type 1 (GLUT 1) deficiency syndrome is characterized by an encephalopathy marked by childhood epilepsy that is refractory to treatment, deceleration of cranial growth leading to microcephaly, psychomotor retardation, spasticity, ataxia, dysarthria and other paroxysmal neurological phenomena often occurring before meals. Symptoms appear between the age of 1 and 4 months, following a normal birth and gestation. 